\title{
Next-Generation Sequencing-Based Pre-Implantation Genetic Testing for Aneuploidy (PGT-A): First Report from Saudi Arabia
}

\author{
Yusra Alyafee ${ }^{1}$, Qamre Alam ${ }^{1}$, Abeer Al Tuwaijii ${ }^{1}$, Muhammad Umair ${ }^{1}$, Shahad Haddad ${ }^{1}$, Meshael Alharbi ${ }^{1}$, \\ Hayat Alrabiah ${ }^{2}$, Maha Al-Ghuraibi ${ }^{2}$, Sahar Al-Showaier ${ }^{2}$ and Majid Alfadhel 1,3,*(D) \\ 1 King Abdullah International Medical Research Center (KAIMRC), Medical Genomics Research Department, \\ King Saud Bin Abdulaziz University for Health Sciences, King Abdulaziz Medical City, \\ Ministry of National Guard Health Affairs (MNG-HA), Riyadh 11426, Saudi Arabia; \\ ahmedyu@ngha.med.sa (Y.A.); alamqa@ngha.med.sa (Q.A.); altuwaijriab@NGHA.MED.SA (A.A.T.); \\ Umairmu@ngha.med.sa (M.U.); haddadsh@ngha.med.sa (S.H.); harbim7@ngha.med.sa (M.A.) \\ 2 Reproductive Endocrinology and Infertility Unit, King Abdulaziz Medical City, \\ Ministry of National Guard Health Affairs (MNG-HA), Riyadh 11426, Saudi Arabia; \\ RabieaaH@NGHA.MED.SA (H.A.); GhuraibiM@ngha.med.sa (M.A.-G.); sa7ar222@hotmail.com (S.A.-S.) \\ 3 Genetics and Precision Medicine Department (GPM), King Abdullah Specialized Children's Hospital, \\ King Saud Bin Abdulaziz University for Health Sciences, King Abdulaziz Medical City, Ministry of National \\ Guard Health Affairs (MNG-HA), Riyadh 11426, Saudi Arabia \\ * Correspondence: dralfadhelm@gmail.com; Tel.: +966-11-805-3560; Fax: +966-11-805-5555
}

Citation: Alyafee, Y.; Alam, Q.; Tuwaijri, A.A.; Umair, M.; Haddad, S.; Alharbi, M.; Alrabiah, H.;

Al-Ghuraibi, M.; Al-Showaier, S.; Alfadhel, M. Next-Generation Sequencing-Based Pre-Implantation Genetic Testing for Aneuploidy (PGT-A): First Report from Saudi Arabia. Genes 2021, 12, 461. https:// doi.org/10.3390/genes12040461

Academic Editors: Richard Choy and Mahesh Choolani

Received: 31 January 2021

Accepted: 17 March 2021

Published: 24 March 2021

Publisher's Note: MDPI stays neutral with regard to jurisdictional claims in published maps and institutional affiliations.

Copyright: (C) 2021 by the authors. Licensee MDPI, Basel, Switzerland. This article is an open access article distributed under the terms and conditions of the Creative Commons Attribution (CC BY) license (https:/ / creativecommons.org/licenses/by/ $4.0 /)$.

\begin{abstract}
Recently, high-throughput next-generation sequencing (NGS)-based preimplantation genetic testing for aneuploidies techniques came into use. This technique is essential for successful embryo transfer and accomplishing pregnancy, thus reducing the time and cost of additional cycles. In this study, we describe our first experience in introducing an NGS-based preimplantation genetic testing for aneuploidy (PGT-A) service using next-generation sequencing in King Abdulaziz Medical City located in Riyadh, Saudi Arabia. Our main goal was to report the successful implementation of this new technology in clinical practice and highlight the factors that may affect the results. In total, 200 blastomere biopsies were obtained from 36 in vitro fertilization (IVF) cycles from Saudi couples suffering from prolonged infertility or recurrent embryo transfer failure. NGS-based PGT-A was performed in all embryos. The results were analyzed in five age groups, showing that aneuploidy rates increased with maternal age. Moreover, the results also showed that complex abnormal embryos with (2-5) aneuploidy are the most common type of embryos. Additionally, our data showed that chromosome 16-related abnormality was the most frequent abnormality detected among all reported abnormalities. In conclusion, our study suggests that NGS-based PGT-A is an applicable and reliable technique for routine-based embryo screening, especially for couples suffering from recurrent miscarriages or multiple embryo transfer failures.
\end{abstract}

Keywords: aneuploidy; embryos; euploidy; preimplantation genetic testing for aneuploidy (PGTA)

\section{Introduction}

Congenital abnormalities and chromosomal abnormalities in the fetus are considered one of the most important causes of infant abnormality or death [1]. One type of chromosomal abnormality is aneuploidy, which is defined as the gain or loss of one or more chromosomes from the normal chromosome number of 46 [2]. Down syndrome or trisomy 21 (T21) is one of the most common chromosomal abnormalities, occurring with a frequency of 1 per 800 live births [3], with a prevalence of 6.6 per 10,000 children in Saudi Arabia [4]. Trisomy 18 (T18), also known as Edward syndrome, and trisomy 13 (T13), also known as Patau syndrome, are amongst the most prevalent autosomal aneuploidies, with an incidence of 1 per 5000 live births for Trisomy 18 and 1 per 16,000 live births for Trisomy 13, respectively $[5,6]$. Furthermore, $6.7 \%$ of recurrent pregnancy loss is caused by chromosomal abnormalities in Saudi Arabia [7]. 
It is well established that a high incidence of chromosomal aneuploidy in human embryos, as well as oocytes, contributes to low implantation and pregnancy rates. These aneuploidies mostly occur due to errors in chromosome segregation during female meiosis and less often during consecutive embryo mitosis [8,9]; male meiosis is rarely a cause of embryonic aneuploidies. Therefore, it is crucial to address this problem by testing embryos prior to implantation into the mother's uterus [10].

Most of the embryo selection methods that have been used previously were based on the detailed morphology of embryos. It has been demonstrated that the optimal morphological characteristics could correlate to higher implantation rates; however, morphology is a weak predictor of implantation rate and ploidy $[11,12]$ The most common technique, still in use today for preimplantation genetic testing for aneuploidy (PGT-A), is microscopic morphology analysis [13]. However, there are many developmental abnormalities that do not affect embryo morphology. Additionally, about $50 \%$ of good morphology embryos can be aneuploid at the blastocyst stage [14]. Therefore, embryo biopsy is required for more accurate aneuploidy detection.

Despite all the controversy about which biopsy approach is more feasible or better for implantation $[15,16]$, the current procedures for biopsy are either by cleavage-stage biopsy at day three or by trophectoderm biopsy at day five or six of the blastocyst stage. Furthermore, the embryo mosaicism phenomenon, which occurs in an early stage of human embryo development, should be also taken into consideration for more accurate aneuploidy detection [17].

There are several techniques used to determine chromosomal aneuploidy in human in vitro fertilization (IVF) embryos, one of which is fluorescence in situ hybridization (FISH). Previously, this was the gold standard technique to perform pre-implantation genetic screening, currently known as preimplantation genetic testing for aneuploidies (PGT-A) [13]. Fluorescence probes are employed to detect selected chromosomes and estimate their numbers. While it is easy to perform, its limitation lies in the ambiguity and difficulty of the interpretation of results, thus resulting in a high rate of false-positive and false-negative results. Another caveat is the inability to check more than five chromosomes in parallel [11].

In recent years, more advanced molecular tools such as array comparative genomic hybridization (CGH), single-nucleotide polymorphism (SNP) array, quantitative real-time polymerase chain reaction (qPCR), and next-generation sequencing (NGS) have been developed [10]. Until recently, qPCR and array-based technologies (SNP array and array CGH) were considered the most viable tools for PGT-A [18]. However, with a significant reduction in cost, NGS has become the technique of choice because of the additional data obtained.

PGT-A by NGS quantifies the number of chromosomes in each embryo biopsy to differentiate between chromosomally normal (euploid) embryos with 46 chromosomes and chromosomally abnormal (aneuploid) embryos [11,12]. This technique offers many advantages, perhaps the most important of which is the decreased risk of miscarriage [13]. Second, NGS-based PGT-A has a high detection rate (98\%) of genetic abnormalities [19]. Thirdly, it can increase the pregnancy rate $[19,20]$. Finally, it reduces the number of IVF cycles needed to achieve pregnancy, potentially reducing the time and cost of extra cycles, as reported by a recent study where it decreased the overall cost by $10 \%[8,9,11]$.

Moreover, several studies have shown the feasibility of the same application by using embryo cell-free DNA from spent culture media without the need to perform invasive biopsies for the embryos [21]. However, more validation and optimization are needed for this approach to be implemented clinically.

In this study, we describe our experience in establishing a PGT-A service in King Abdulaziz Medical City located in Riyadh, Saudi Arabia. Our main goal was to report our experience of the implementation of this new technology in clinical practice. Our second goal was to investigate and explore factors that may contribute to the aneuploidy rates of 
the embryos. In conclusion, to the best of our knowledge this is the first study highlighting the experience of the integration of NGS-based PGT-A in a clinical setting in Saudi Arabia.

\section{Material and Methods}

Study Approval and Consent

This study was approved by the IRB with approval number RC19/115/R of King Abdullah International Medical Research Centre (KAIMRC), Riyadh, Saudi Arabia. Participants went through a full clinical assessment at Reproductive Endocrinology and Infertility Unit National Guard Hospital (NGH), Riyadh, Saudi Arabia. Written informed consent forms for conducting the procedure for this study and dissemination of clinical data were signed by all the families included in this study.

\section{Study Subjects}

Inclusion criteria were Saudi couples suffering from prolonged infertility ( $>4$ years), with/without advanced maternal age (>36 completed years), or recurrent embryo transfer failure ( $\geq 10$ embryos in multiple transfers) with no history of previous pregnancy outcome by regular IVF cycle from October 2019 to October 2020. Exclusion criteria included women with contraindications for IVF/ICSI, Body mass index (BMI) $>30 \mathrm{~kg} / \mathrm{m}^{2}$, poor quality embryos not suitable for biopsy, and finally low total antral follicle count ( $<7$ follicles).

\subsection{Genomic DNA Extraction from Blastomere Biopsy}

Blastomeres biopsies at day 3 (cleavage stage) were performed on 200 embryos obtained from participants after 36 IVF cycles. Genomic DNA extraction experiments were performed on all biopsies, including quality control samples (confirmed euploid and aneuploid biopsies) using the Ion Single Seq ${ }^{\mathrm{TM}}$ Kit (Part No. A28955, Hilden, Germany) according to the manufacturer's protocol. The aspirated 1-2 cells were transferred to a PCR tube containing $2.5 \mu \mathrm{L} 1 \times$ PBS. A total of $2.5 \mu \mathrm{L}$ of cell extraction buffer and $5 \mu \mathrm{L}$ of extraction enzyme master mix were added to each sample (10 $\mu \mathrm{L}$ total volume). PCR tubes were spun at $1000 \times g$ for $30 \mathrm{~s}$ to collect liquid at the bottom of the tube [22,23]. Finally, the standard thermal cycler conditions used were $75^{\circ} \mathrm{C}$ for $10 \mathrm{~min}$, followed by $95^{\circ} \mathrm{C}$ for 4 min and holding at $22{ }^{\circ} \mathrm{C}[22,23]$. The PCR was performed in a Veriti ${ }^{\mathrm{TM}}$ 96-Well Thermal Cycler (Applied Biosystem TM, Foster City, CA, USA, Cat. No\# 4375786).

\subsection{Pre-Amplification of Genomic DNA}

A pre-amplification genomic DNA experiment was performed using an Ion Single Seq ${ }^{\mathrm{TM}}$ Kit (Part No. A28955, Hilden, Germany) according to the manufacturer's protocol. A total of $5 \mu \mathrm{L}$ of pre-amplification enzyme master mix was added to each sample. The PCR tubes were centrifuged at $1000 \times g$ for $30 \mathrm{~s}$ to collect liquid at the bottom of the tube. The PCR tubes were kept in a thermal cycler [24]. Finally, the standard thermal cycler conditions used were $95^{\circ} \mathrm{C}$ for $2 \mathrm{~min}(1 \mathrm{Cycle})$, followed by $95^{\circ} \mathrm{C}$ for $15 \mathrm{~s}, 15^{\circ} \mathrm{C}$ for $50 \mathrm{~s}$, $25^{\circ} \mathrm{C}$ for $40 \mathrm{~s}, 35^{\circ} \mathrm{C}$ for $30 \mathrm{~s}, 65^{\circ} \mathrm{C}$ for $40 \mathrm{~s}$, and $75^{\circ} \mathrm{C}$ for $40 \mathrm{~s}$ (12 cycle) [25]. The PCR was performed in Veriti ${ }^{\mathrm{TM}}$ 96-Well Thermal Cycler (Applied Biosystem ${ }^{\mathrm{TM}}$, Foster City, CA, USA, Cat. No\# 4375786).

\subsection{Amplification of DNA Libraries}

Amplification libraries were performed using an Ion Single Seq ${ }^{\mathrm{TM}}$ Kit (Part No. A28955, Hilden, Germany) according to the manufacturer's protocol. A total of $30 \mu \mathrm{L}$ of amplification master mix (amplification buffer, amplification enzyme, and nuclease-free water) was added to each sample. After that, $5 \mu \mathrm{L}$ of the Ion Single Seq ${ }^{\text {TM }}$ barcode adapter was added to each sample tube (total volume $50 \mu \mathrm{L}$ ). Each barcode adapter is single-use only. Then, we mixed the samples by pipetting up and down, using a new tip for each sample, and centrifuging them at $1000 \times \mathrm{g}$ for $30 \mathrm{~s}$ to collect liquid at the bottom of the wells. Finally, the standard thermal cycler conditions used were $95^{\circ} \mathrm{C}$ for $3 \mathrm{~min}(1 \mathrm{Cycle})$ followed by $95^{\circ} \mathrm{C}$ for $20 \mathrm{~s}, 50{ }^{\circ} \mathrm{C}$ for $25 \mathrm{~s}$, and $72{ }^{\circ} \mathrm{C}$ for $40 \mathrm{~s}$ (4 Cycles). After that, $95^{\circ} \mathrm{C}$ for $20 \mathrm{~s}, 72{ }^{\circ} \mathrm{C}$ for 
$55 \mathrm{~s}$ (12 cycle) and holding at $4{ }^{\circ} \mathrm{C}[26,27]$. The PCR was performed in the Veriti ${ }^{\mathrm{TM}}$ 96-Well Thermal Cycler (Applied Biosystem ${ }^{\mathrm{TM}}$, Foster City, CA, USA, Cat. No\# 4375786).

\subsection{Pool, Purify, and Quantification of the DNA Libraries}

A total of $40 \mu \mathrm{L}$ of the DNA library pool was transferred to a $0.2 \mathrm{~mL}$ PCR tube to each sample. The tubes were heated to $72{ }^{\circ} \mathrm{C}$ for 2 min and held at $22^{\circ} \mathrm{C}$. After that, the tubes were briefly spined to collect the samples at the bottom of the tube and then transferred to the heated DNA library pool to a $1.5 \mathrm{~mL}$ LoBind Eppendorf tube. To each tube, $40 \mu \mathrm{L}$ of AMP pure XP beads were added to purify the DNA libraries. The remaining step of purification was performed using the kit's protocol. Finally, quantification DNA libraries were obtained using the protocol of Qubit ds DNA HS assay kit (Invitrogen ${ }^{\mathrm{TM}}$, Waltham, MA, USA, Cat. No\# Q32851).

\subsection{Loading of DNA Libraries Pool into Ion Chef ${ }^{\mathrm{TM}}$ Equipment}

The Ion Chef ${ }^{\mathrm{TM}}$ reagent was kept outside at room temperature for $45 \mathrm{~min}$ before the loading of the libraries. Other consumables and solution cartridges were placed at an appropriate position into the Ion Chef ${ }^{\mathrm{TM}}$ equipment (Thermo Fisher Scientific, Waltham, MA, USA, Cat. No\# 4484177) [27]. The samples were run into batches of 16 (using 510 ${ }^{\mathrm{TM}}$ ). Finally, $4 \mu \mathrm{L}$ of the $1 \mathrm{nM}$ pooled library was transferred to position A of the reagent cartridge, and $46 \mu \mathrm{L}$ of NFW was added to give a final concentration of $80 \mathrm{pM}$ [24]. The complete workflow from sample processing to reporting was completed in 12-16 h depending on the number of samples taken simultaneously [25].

\subsection{Initialization and Sequencing Run into Ion $S 5^{\mathrm{TM}}$}

The Ion S5 ${ }^{\mathrm{TM}}$ ExT Sequencing Reagents cartridge was kept for $45 \mathrm{~min}$ to equilibrate the reagent at room temperature. After that, Sequencing Reagents cartridge, Ion S5 ${ }^{\mathrm{TM}}$ ExT Wash Solution bottle, and Ion S5 ${ }^{\mathrm{TM}}$ Cleaning Solution bottle were kept at an appropriate position in the Ion S5 ${ }^{\mathrm{TM}}$ instrument (Thermo Fisher Scientific, Waltham, MA, USA, Cat. No\# A27212). Finally, the Ion $510^{\mathrm{TM}}$ chip (Cat. No \# A34292) was used to perform initialization. After the completion of initialization ( $\sim 50 \mathrm{~min})$, the instrument was ready for a sequencing run $[28,29]$.

\subsection{Bioinformatics Analysis and Interpretation of NGS Data}

For data analysis, the sequencing data acquired by the IonS5 ${ }^{\mathrm{TM}}$ sequencer were processed and transferred to Ion Reporter ${ }^{\mathrm{TM}}$ software. This software uses the bioinformatics tool ReproSeq w1.1 work flow to detect 24-chromosome aneuploidies from a single whole-genome sample with a low coverage [30]. Normalization was performed using the bioinformatics baseline ReproSeq Low-Coverage Whole-Genome Baseline generated from multiple normal samples. The Analysis Visualization screen opens to the IRGV Table A copy number histogram for each selected analysis appears, along with ploidy maps for selected chromosomes or chromosome regions, and karyograms showing copy number gains and losses $[11,29,30]$. For the purpose of this study, embryos were categorized into seven groups: euploid (no gain or loss), single-chromosome aneuploidy (only one chromosome involved), complex aneuploidy embryos ( $2-5$ chromosomes involved either gain or loss or both), chaotic aneuploidy embryos ( $>5$ chromosomes involved), and finally poor quality and non-informative embryos (failure of amplification), as seen in Figure 1 for a representative image of the results. 
A)

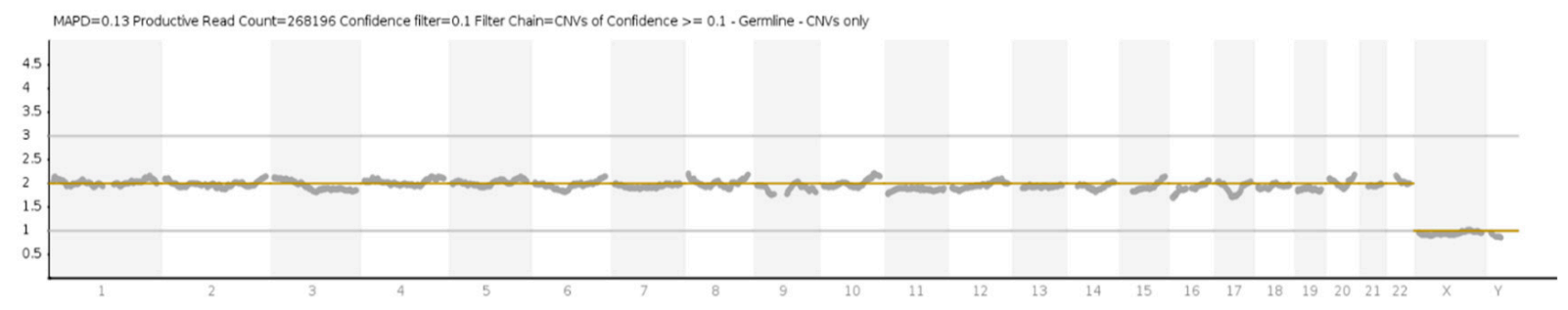

B)
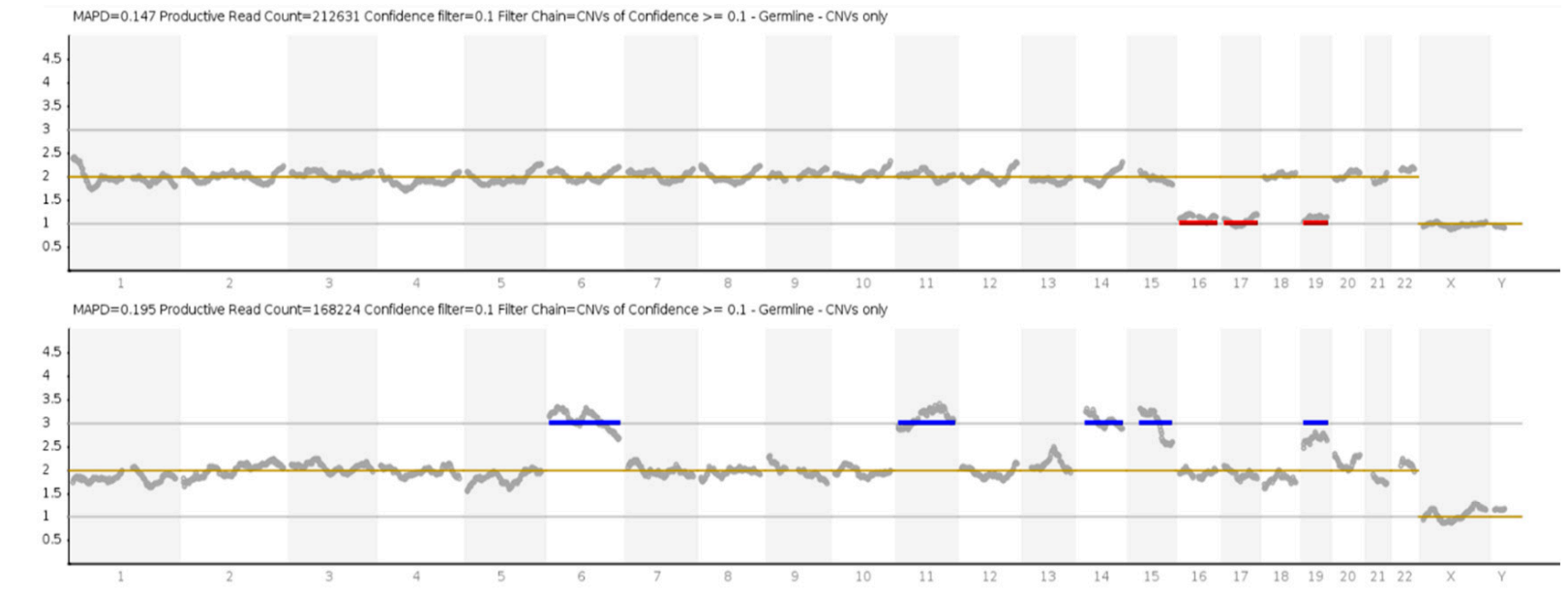

C)

D)

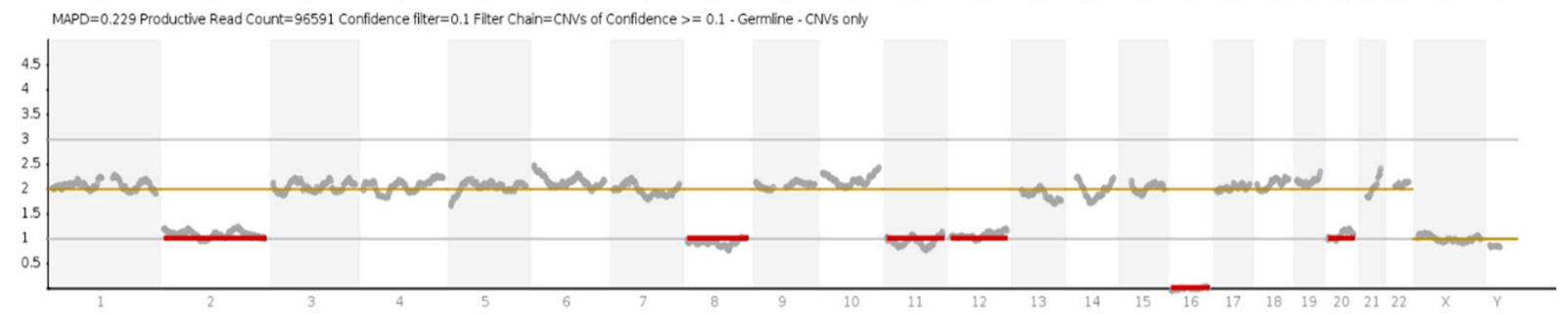

Figure 1. Images of ion reporter genomic viewer for different embryos. (A) Result of a euploid male embryo. (B) Result of complex aneuploidy embryo depicting three monosomies at chromosome number 16, 17, and 19. (C) Result of complex aneuploidy embryo depicting five trisomies at chromosome number 6, 11, 14, 15, and 19. (D) Result of chaotic (more than 5 aneuploidies) depicting aneuploidies at chromosomes number $2,8,11,12,16$, and 20.

\section{Results}

In our study, blastomere biopsies from 200 embryos obtained from 36 IVF cycles (average 5.6 embryos/couple) were recruited for PGT-A using high-throughput DNA sequencing-based Ion S5 technology. Almost all of the participants were of Saudi ethnicity. The average age of all the women who participated in IVF was 35.15 years with a range of 25 to 47 years, while the average age of male participants was 44.6 ranging between 33 and 67 years. All of the general information about the participants and biopsies is summarized in Table 1.

Table 1. Next-generation sequencing (NGS) results of 36 preimplantation genetic testing for aneuploid(PGT-A) cycles performed in day 3 biopsies.

\begin{tabular}{lccc}
\hline \multicolumn{1}{c}{ Results } & & Percentage \% & Standard Deviation \\
\hline No of the embryos & 200 & 100 & \\
analyzed & 35.15 & - & 4.64 \\
Mean female age & 44.5 & - & 8.95 \\
Mean male age & 166 & 83 & \\
Informative embryos & 46 & 23 & \\
Euploid embryos & 120 & 60 & \\
Aneuploid embryos & & & \\
\hline
\end{tabular}


Out of 200 samples, 46 (23\%) embryos were found to be euploid and hence recommended for transfer into the respective mother's uterus with an overall pregnancy rate of $17 \%$. On the other hand, $120(60 \%)$ embryos were found to be aneuploid and hence, these embryos were not recommended for transfer into the mother's uterus. Moreover, out of 120 aneuploid embryos, we found $57(28.5 \%)$ complex, $33(16.5 \%)$ chaotic, $20(10 \%)$ singlechromosome aneuploidy, and finally 7 (3.5\%) partial chromosome abnormal embryos. In addition, we found $34(17 \%)$ poor-quality embryos; these embryos were not recommended for transfer but were recommended for re-biopsy if possible. Various types of chromosomal aneuploidies/aneuploidies are summarized in Table 2.

Table 2. General PGT-A outcomes of all the embryos recruited in this study.

\begin{tabular}{llccc}
\hline \multicolumn{1}{c}{ Result } & $\begin{array}{c}\text { Number of } \\
\text { Embryos }\end{array}$ & $\begin{array}{c}\text { Percentage of } \\
\text { Total }\end{array}$ & $\begin{array}{c}\text { Recommendation } \\
\text { for Transfer }\end{array}$ & Pregnancy Rate \\
\hline Euoploidy & & 46 & 23 & YES \\
\hline \multirow{3}{*}{ Aneuploidy } & Complex Abnormal Embryo & 57 & 28.5 & NO \\
\cline { 2 - 5 } & Chaotic Abnormal Embryo & 33 & 16.5 & NO \\
\cline { 2 - 5 } & Single Chromosome Aneuploidy & 20 & 10 & NO \\
\cline { 2 - 5 } & Partial Chromosome Abnormality & 7 & 3.5 & NO \\
\cline { 2 - 5 } & Mosaic Embryo & 3 & 1.5 & NO \\
\hline Poor quality embryo & 34 & 17 & $17 \%$ \\
\hline
\end{tabular}

Furthermore, the number of euploidies and aneuploidies in different maternal age groups were also examined and divided into four groups viz 25-30, 31-35, 36-40, and $\geq 40$ years. In the first age group of 25-30 years, out of 37 embryos, 9 (24.3\%) were euploid while 21 (56.8\%) were aneuploid. In the second group 31-35 years, out of 59 embryos, 19 $(32.2 \%)$ were euploid while 35 (59.3\%) were aneuploid. In the third group of 36-40 years, out of 69 embryos, 17 (24.6\%) were euploid while 42 (60.9\%) were aneuploid. Finally, in the last age group, which is more than 40 years, out of 35 embryos, $8(22.9 \%)$ were euploid while 22 (62.9\%) were aneuploid. In comparison, increased age in the paternal side did not show any influence related to the total number of euploidy and aneuploidy. All the frequencies of euploidy/aneuploidy in IVF embryos of women participants within different age groups are summarized in Table 3.

Table 3. Frequency of euploidy / aneuploidy in in vitro fertilization (IVF) embryos of maternal and paternal participants within different age groups.

\begin{tabular}{|c|c|c|c|c|c|c|c|c|}
\hline Gender & $\begin{array}{c}\text { Age } \\
\text { (Years) }\end{array}$ & $\begin{array}{l}\text { No. of } \\
\text { Embryos }\end{array}$ & $\begin{array}{c}\text { No. } \\
\text { Euploidy }\end{array}$ & $\begin{array}{c}\% \text { of } \\
\text { Euploidy }\end{array}$ & $\begin{array}{c}\text { No. of } \\
\text { Aneuploidy }\end{array}$ & $\begin{array}{c}\% \text { of } \\
\text { Aneuploidy }\end{array}$ & $\begin{array}{l}\text { No. of Poor } \\
\text { Quality }\end{array}$ & $\begin{array}{c}\% \text { of Poor } \\
\text { Quality }\end{array}$ \\
\hline \multirow{4}{*}{ Maternal } & $25-30$ & 37 & 9 & 24.3 & 21 & 56.8 & 7 & 18.9 \\
\hline & $31-35$ & 59 & 19 & 32.2 & 35 & 59.3 & 5 & 8.5 \\
\hline & $36-40$ & 69 & 17 & 24.6 & 42 & 60.9 & 10 & 14.5 \\
\hline & $\geq 40$ & 35 & 8 & 22.9 & 22 & 62.9 & 5 & 14.3 \\
\hline \multirow{4}{*}{ Paternal } & $36-40$ & 78 & 10 & 12.5 & 50 & 64.1 & 18 & 23.1 \\
\hline & $41-45$ & 58 & 8 & 13.8 & 44 & 75.8 & 6 & 10.3 \\
\hline & $46-50$ & 12 & 2 & 16.6 & 8 & 66.7 & 2 & 16.6 \\
\hline & $\geq 50$ & 62 & 14 & 22.6 & 34 & 54.8 & 14 & 22.6 \\
\hline
\end{tabular}

Moreover, we also analyzed our data based on different types of aneuploidies such as monosomy, trisomy, complex, and chaotic in different age groups of women. We found $11(9.2 \%)$ trisomy, 9 (7.5\%) monosomy, 7 (5.8\%) partial deletion, 57 (47.5\%) complex, and $33(27.5 \%)$ chaotic in the above-mentioned age groups. All these different types of chromosomal aneuploidies in different age groups are summarized in Table 4. 
Table 4. Types of aneuploidies found in the IVF embryos of recruited women of different age groups.

\begin{tabular}{ccccccc}
\hline Age (Years) & T & M & PD & Mo & Complex & Chaotic \\
\hline $25-30$ & 2 & 2 & 2 & 1 & 9 & 5 \\
$31-35$ & 5 & 2 & 1 & - & 17 & 10 \\
$36-40$ & 3 & 5 & 4 & 2 & 14 & 14 \\
$\geq 40$ & 1 & - & - & - & 17 & 4 \\
Total & 11 & 9 & 7 & 3 & 57 & 33 \\
\% of Total & 9.2 & 7.5 & 5.8 & 2.5 & 47.5 & 27.5 \\
\hline
\end{tabular}

T: Trisomy; M: Monosomy; PD: Partial Deletion; Mo: Mosaic Complex: 2 to 5 aneuploidies in the same embryo, Chaotic: More than 5 aneuploidies in the same embryo. No significant differences were found between different age groups and different types of abnormalities.

Finally, we analyzed the prevalence of aneuploid frequency in various autosomal chromosomes (1-22 pairs). The results showed that aneuploidies of chromosome 16 (30\%), $11(24 \%)$, and $4(22 \%)$ reflect much more frequent aneuploidies than any others, as shown in Figure 2.

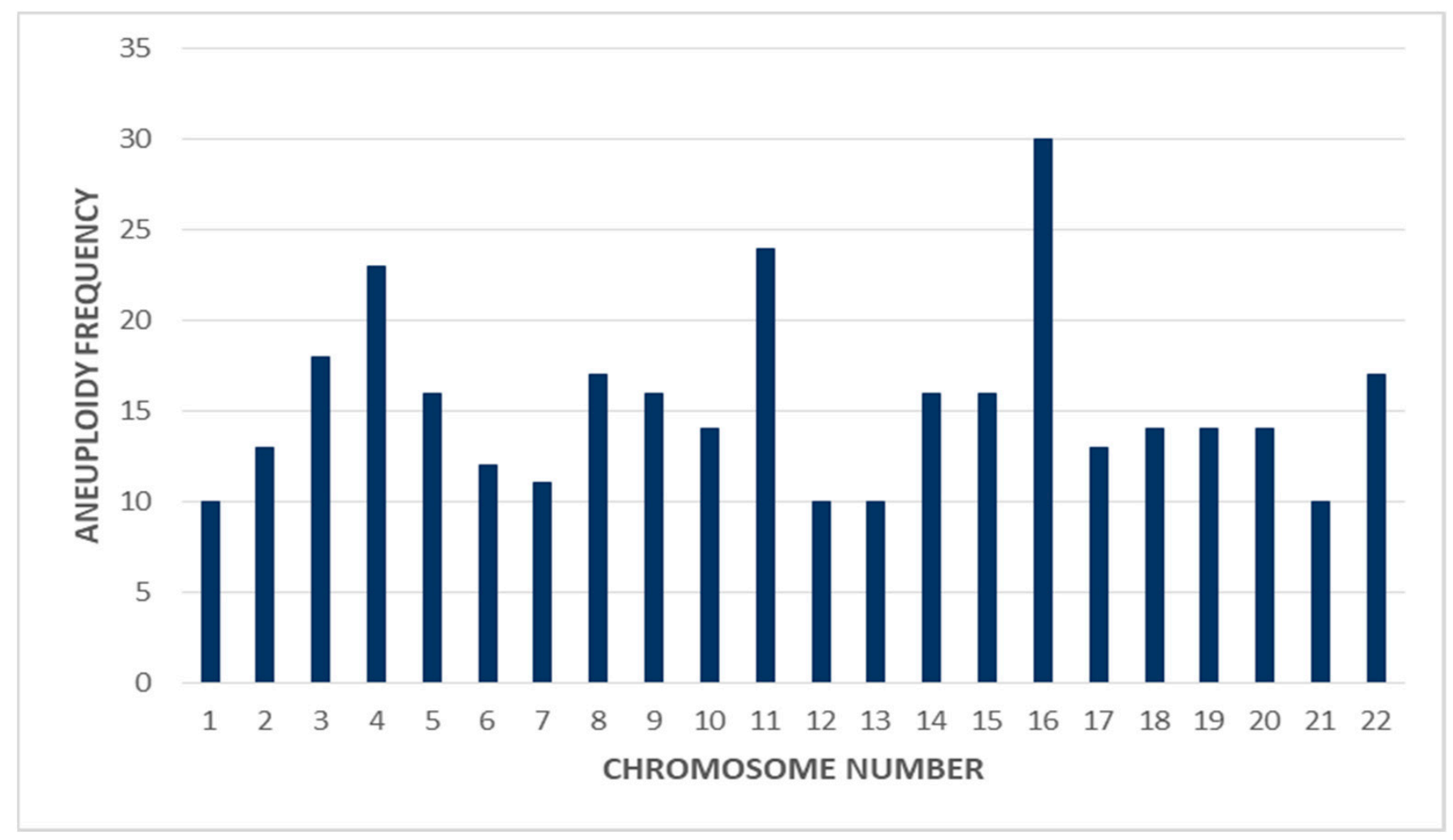

Figure 2. Frequency of aneuploidy for all autosomal chromosomes.

\section{Discussion}

In the current study, the NGS-based PGT-A technique was performed for 200 IVF embryos included in this study. It is well known that a high incidence of chromosomal aneuploidies in the human oocyte/embryo occurs in women over the age of 35 years, which consequently contributes to miscarriage and hence a low pregnancy rate after IVF implantation [11].

Therefore, maternal age is a major concern for aneuploidy and genetic disorders in the offspring in the context of the rise of IVF in mothers of increasingly older ages [12]. The association of a mother's age and chromosomal aneuploidy in a fetus is also reflected in our study. Among the 69 IVF samples investigated in the age group of 36-40 years, only 17 $(24.6 \%)$ were euploid (normal), while 42 (60.9\%) showed aneuploidy (abnormal). 
Furthermore, out of 35 embryos, 8 (22.9\%) were euploid and 22 (62.9\%) were aneuploid in the mothers whose age group was more than 40 years. In addition, complex and chaotic types of chromosomal aneuploidies were also reflected in the age group of more than 35 years. The rate of aneuploidy increased in the group of mothers over 31 years compared to the group of mothers aged less than 31 years, confirming previous trends where aneuploidy increases as the age of the mother increases [26]. In addition, in this study, we did not detect any significant influence of the paternal age on the number of euploid and aneuploid embryos. However, we cannot exclude bias related to maternal age [31].

Moreover, our result showed that the highest frequency of chromosomal abnormalities involved chromosome 16 , as it appeared in $25 \%$ of all the aneuploid embryos. This finding is in accordance with previously reported data about the relation of chromosome 16 aneuploidies with frequent miscarriage and the involvement of maternal meiosis errors in the process [30]. Although not all euploid embryos transferred to their corresponding mothers yet the overall pregnancy rate was found to be $17 \%$. Moreover, one mosaic embryo was also transferred to the mother upon the couple's request and after detailed proper counseling, as many previous studies found that mosaic embryo can result in a healthy normal baby [32].

Consequently, the major advantages of testing embryos of those patients before implantation into the mother's uterus are clear. Despite the various techniques that have been used previously, this study has shown that the NGS-based PGT-A platform could be a gold-standard technique for successful IVF technology. This technique has been shown to increase the chances of implantation in our study, and enabled genetically normal embryos to be transferred, thus avoiding the health complications associated with twin or triplet pregnancies.

\section{Conclusions}

This study showed the feasibility of NGS-based PGT-A in detecting chromosomal aneuploidy in the embryos. This helped the couples in our study to understand the reasons for their related infertility conditions. Moreover, it demonstrated the ability to transfer chromosomally normal embryos to increase their chances to achieve pregnancy. However, more time will be needed in order to overcome the mosaicism limitation of PGT-A that greatly affects the detection rate. To the best of our knowledge, this is the first study highlighting the experience of NGS-based PGT-A for embryo screening in a clinical care setting in Saudi Arabia. Its implication for practice could avoid the limitations of current methods and greatly benefit Saudi mothers struggling with pregnancy.

Author Contributions: M.A. (Majid Alfadhel): Designed and wrote the project; Y.A.: Project management, data analysis, and revised the manuscript; Q.A.: wrote draft manuscript; M.U., A.A.T. and H.A.: Manuscript editing; S.H. and M.A. (Meshael Alharbi): Performed the experiments; S.A.-S. and M.A.-G.: Patients recruitments and embryos biopsies. All authors have read and agreed to the published version of the manuscript.

Funding: The King Abdullah International Medical Research Centre, project number, funded this work: RC19/115/R.

Institutional Review Board Statement: The study was conducted following the guidelines of the Declaration of Helsinki, and approved by the ethics committee of King Abdullah International Medical Research Centre, Riyadh, Saudi Arabia (protocol code RC19/115/R and date of approval /July/2019).

Informed Consent Statement: Informed and detaild consent was obtained from all subjects participated in the study.

Data Availability Statement: The supporting data on the findings of this study will be provided by the corresponding author on reasonable request. 
Acknowledgments: The authors thank the couples for participating in this study. We extend our appreciation to the Department of Pathology and Laboratory Medicine in King Abdul Aziz Medical City for their support in this study.

Conflicts of Interest: The authors have reported no conflict of interest.

Ethical Standards: All procedures were approved by the research committee of King Abdullah International Medical Research Centre, Riyadh, Saudi Arabia (IRB NCBE registration No: H-01-R005) and were performed following the ethical standards. Written informed consent was obtained.

$\begin{array}{ll}\text { Abbreviations } \\ \text { PGT-A } & \text { Pre-Implantation Genetic Testing for Aneuploidy } \\ \text { PGS } & \text { Pre-Implantation Genetic Screening } \\ \text { PGD } & \text { Pre-Implantation Genetic Diagnosis } \\ \text { IVF } & \text { In vitro Fertilization } \\ \text { PCR } & \text { Polymerase Chain Reaction } \\ \text { NSG } & \text { Next-Generation sequencing } \\ \text { FISH } & \text { Fluorescence in situ hybridization } \\ \text { NFW } & \text { Nuclease Free Water } \\ \text { IRB } & \text { Institution Review Board } \\ \text { NGHA } & \text { National Guard Health Affairs } \\ \text { KAIMRC } & \text { King Abdullah International Medical Research Center }\end{array}$

\section{References}

1. Alberti, A.; Salomon, L.J.; Le Lorc'h, M.; Couloux, A.; Bussières, L.; Goupil, S.; Malan, V.; Pelletier, E.; Hyon, C.; Vialard, F.; et al Non-invasive prenatal testing for trisomy 21 based on analysis of cell-free fetal DNA circulating in the maternal plasma. Prenat Diagn. 2015, 35, 471-476. [CrossRef]

2. Badeau, M.; Lindsay, C.; Blais, J.; Nshimyumukiza, L.; Takwoingi, Y.; Langlois, S.; Légaré, F.; Giguère, Y.; Turgeon, A.F.; Witteman, W.; et al. Genomics-based non-invasive prenatal testing for detection of fetal chromosomal aneuploidy in pregnant women. Cochrane Database Syst. Rev. 2017, 11, Cd011767. [CrossRef]

3. Benachi, A.; Letourneau, A.; Kleinfinger, P.; Senat, M.V.; Gautier, E.; Favre, R.; Bidat, L.; Houfflin-Debarge, V.; Bouyer, J.; Costa, J.M. Cell-free DNA analysis in maternal plasma in cases of fetal abnormalities detected on ultrasound examination. Obstet. Gynecol. 2015, 125, 1330-1337. [CrossRef] [PubMed]

4. Wu, Y.; Zhang, L.; Lv, H.; Li, Y.; Zhu, C.; Tian, W.; Zhao, L. Applying high-throughput sequencing to identify and evaluate foetal chromosomal deletion and duplication. J. Cell Mol. Med. 2020, 24, 9936-9944. [CrossRef] [PubMed]

5. Cuckle, H.; Maymon, R. Development of prenatal screening-A historical overview. Semin. Perinatol. 2016, 40, 12-22. [CrossRef] [PubMed]

6. Pös, O.; Budiš, J.; Szemes, T. Recent trends in prenatal genetic screening and testing. F1000Research 2019, 8. [CrossRef] [PubMed]

7. Levy, B.; Wapner, R. Prenatal diagnosis by chromosomal microarray analysis. Fertil. Steril. 2018, 109, 201-212. [CrossRef] [PubMed]

8. Ambartsumyan, G.; Clark, A.T. Aneuploidy and early human embryo development. Hum. Mol. Genet. 2008, 17, R10-R15. [CrossRef]

9. Rubio, C.; Mercader, A.; Mateu, E.; Buendía, P.; Pehlivan, T.; Viloria, T.; De los Santos, M.J.; Simón, C.; Remohí, J.; Pellicer, A.; et al. Impact of chromosomal abnormalities on preimplantation embryo development. Prenat. Diagn. 2007, 27, 748-756. [CrossRef]

10. Handyside, A.H. 24-chromosome copy number analysis: A comparison of available technologies. Fertil. Steril. 2013, 100, 595-602. [CrossRef]

11. Lukaszuk, K.; Jakiel, G.; Kuczynski, W.; Pukszta, S.; Liss, J.; Plociennik, L.; Lukaszuk, A.; Pastuszek, E. Next generation sequencing for preimplantation genetic testing of blastocysts aneuploidies in women of different ages. Ann. Agric. Environ. Med. 2016, 23, 163-166. [CrossRef] [PubMed]

12. Treff, N.R.; Forman, E.J.; Scott, R.T., Jr. Next-generation sequencing for preimplantation genetic diagnosis. Fertil. Steril. 2013, 99, e17-e18. [CrossRef]

13. Gianaroli, L.; Magli, M.C.; Ferraretti, A.P.; Fortini, D.; Grieco, N. Pronuclear morphology and chromosomal abnormalities as scoring criteria for embryo selection. Fertil. Steril. 2003, 80, 341-349. [CrossRef]

14. Machtinger, R.; Racowsky, C. Morphological systems of human embryo assessment and clinical evidence. Reprod. Biomed. Online 2013, 26, 210-221. [CrossRef] [PubMed]

15. Scott, K.L.; Hong, K.H.; Scott, R.T., Jr. Selecting the optimal time to perform biopsy for preimplantation genetic testing. Fertil. Steril. 2013, 100, 608-614. [CrossRef]

16. Scott, R.T., Jr.; Upham, K.M.; Forman, E.J.; Hong, K.H.; Scott, K.L.; Taylor, D.; Tao, X.; Treff, N.R. Blastocyst biopsy with comprehensive chromosome screening and fresh embryo transfer significantly increases in vitro fertilization implantation and delivery rates: A randomized controlled trial. Fertil. Steril. 2013, 100, 697-703. [CrossRef] 
17. Capalbo, A.; Ubaldi, F.M.; Rienzi, L.; Scott, R.; Treff, N. Detecting mosaicism in trophectoderm biopsies: Current challenges and future possibilities. Hum. Reprod. 2017, 32, 492-498. [CrossRef]

18. Capalbo, A.; Treff, N.R.; Cimadomo, D.; Tao, X.; Upham, K.; Ubaldi, F.M.; Rienzi, L.; Scott, R.T., Jr. Comparison of array comparative genomic hybridization and quantitative real-time PCR-based aneuploidy screening of blastocyst biopsies. Eur. J. Hum. Genet. 2015, 23, 901-906. [CrossRef]

19. Zhang, C.; Zhang, C.; Chen, S.; Yin, X.; Pan, X.; Lin, G.; Tan, Y.; Tan, K.; Xu, Z.; Hu, P.; et al. A single cell level based method for copy number variation analysis by low coverage massively parallel sequencing. PLoS ONE 2013, 8, e54236. [CrossRef]

20. Simpson, J.L.; Rechitsky, S.; Kuliev, A. Next-generation sequencing for preimplantation genetic diagnosis. Fertil. Steril. 2013, 99, 1203-1204. [CrossRef]

21. Yeung, Q.S.Y.; Zhang, Y.X.; Chung, J.P.W.; Lui, W.T.; Kwok, Y.K.Y.; Gui, B.; Kong, G.W.S.; Cao, Y.; Li, T.C.; Choy, K.W. A prospective study of non-invasive preimplantation genetic testing for aneuploidies (NiPGT-A) using next-generation sequencing (NGS) on spent culture media (SCM). J. Assist. Reprod. Genet. 2019, 36, 1609-1621. [CrossRef] [PubMed]

22. Sachdeva, K.; Discutido, R.; Albuz, F.; Almekosh, R.; Peramo, B. Validation of Next-Generation Sequencer for 24-Chromosome Aneuploidy Screening in Human Embryos. Genet. Test. Mol. Biomarkers 2017, 21, 674-680. [CrossRef] [PubMed]

23. Yang, Y.; Liu, Y.; Ma, P.; Chen, J.; Ding, T. Application of next generation sequencing for the preimplantation genetic test of 71 couples with one partner carrying a reciprocal or Robertsonian translocation. Zhonghua Yi Xue Yi Chuan Xue Za Zhi 2020, 37, 563-566. [PubMed]

24. García-Pascual, C.M.; Navarro-Sánchez, L.; Navarro, R.; Martínez, L.; Jiménez, J.; Rodrigo, L.; Simón, C.; Rubio, C. Optimized NGS Approach for Detection of Aneuploidies and Mosaicism in PGT-A and Imbalances in PGT-SR. Genes 2020, 11, 724. [CrossRef]

25. Kung, A.; Bankowski, B.; Coates, A.; Wells, D. Validation of next-generation sequencing for comprehensive chromosome screening of embryos. Reprod. Biomed. Online 2015, 31, 760-769. [CrossRef] [PubMed]

26. Rubio, C.; Rodrigo, L.; Garcia-Pascual, C.; Peinado, V.; Campos-Galindo, I.; Garcia-Herrero, S.; Simón, C. Clinical application of embryo aneuploidy testing by next-generation sequencing. Biol. Reprod. 2019, 101, 1083-1090. [CrossRef]

27. Maxwell, S.M.; Colls, P.; Hodes-Wertz, B.; McCulloh, D.H.; McCaffrey, C.; Wells, D.; Munné, S.; Grifo, J.A. Why do euploid embryos miscarry? A case-control study comparing the rate of aneuploidy within presumed euploid embryos that resulted in miscarriage or live birth using next-generation sequencing. Fertil. Steril. 2016, 106, 1414-1419.e5. [CrossRef] [PubMed]

28. Fiorentino, F.; Biricik, A.; Bono, S.; Spizzichino, L.; Cotroneo, E.; Cottone, G.; Kokocinski, F.; Michel, C.E. Development and validation of a next-generation sequencing-based protocol for 24-chromosome aneuploidy screening of embryos. Fertil. Steril. 2014, 101, 1375-1382. [CrossRef]

29. Alyafee, Y.; Al Tuwaijri, A.; Alam, Q.; Umair, M.; Haddad, S.; Alharbi, M.; Ballow, M.; Al Drees, M.; AlAbdulrahman, A.; Al Khaldi, A.; et al. Next Generation Sequencing Based Non-invasive Prenatal Testing (NIPT): First Report From Saudi Arabia. Front. Genet. 2021, 12, 630787. [CrossRef] [PubMed]

30. Hassold, T.; Merrill, M.; Adkins, K.; Freeman, S.; Sherman, S. Recombination and maternal age-dependent nondisjunction: Molecular studies of trisomy 16. Am. J. Hum. Genet. 1995, 57, 867-874.

31. Chapuis, A.; Gala, A.; Ferrières-Hoa, A.; Mullet, T.; Bringer-Deutsch, S.; Vintejoux, E.; Torre, A.; Hamamah, S. Sperm quality and paternal age: Effect on blastocyst formation and pregnancy rates. Basic Clin. Androl. 2017, 27, 1-9. [CrossRef] [PubMed]

32. Zhang, Y.X.; Chen, J.J.; Nabu, S.; Yeung, Q.S.Y.; Li, Y.; Tan, J.H.; Suksalak, W.; Chanchamroen, S.; Quangkananurug, W.; Wong, P.S.; et al. The Pregnancy Outcome of Mosaic Embryo Transfer: A Prospective Multicenter Study and Meta-Analysis. Genes 2020, 11, 973. [CrossRef] [PubMed] 